\title{
NOTAS SOBRE O ARQUIVO DO ESTADO DE SÃO PAULO
}

\author{
Nilo Odalia \\ Professor aposentado da Unesp e Diretor Técnico do DAE
}

Nāo se pode falar do Arquivo do Estado sem uma referência, ainda que breve, sobre sua história. Sua origem remonta ao século XVIII, mais exatamente ao ano de 1721, quando foi criada a primeira repartição pública da capitania de Sāo Paulo. Esta repartiçăo tinha por finalidade a administração dos papéis do governo da capitania, grande parte dos quais pertence ao acervo pré-republicano do Arquivo. Nāo é, portanto, impertinente dizer-se que o Arquivo do Estado é o natural sucessor dessa primeira instituiçăo pública. Lcgalmente, contudo, e com a designação de Arquivo, seu nascimento data de cerca de 70 anos depois, quando foi criado o Archivo Provincial de São Paulo, por lei, votada pela Assembléia Legislativa da Província de Săo Paulo e sancionada pelo Barăo de Mont'Alcgre, Presidente da Província. A referida Lei foi publicada na Secretaria do Governo de Sáo Paulo, em 8 de março de 1842 , e estabelecida a organizaçāo administrativa do Arquivo, três secçōes (Legislativa, Administrativa e Histórica), sendo que seu artigo $6^{2}$ reza o seguinte:

Artigo $6^{2}-$ Na Secçāo historica serāo archivados os originaes, ou copias authenticas dos actos, ou memorias, que contenhāo:
Parágrafo $1^{\circ}-$ Notícias dos acontecimentos notaveis; todos os documentos officiaes relativos á declaração da Independencia Nacional; e noticias de qualquer descuberta de productos de historia natural, de Patentes conferidas aos Inventores d'algua industria util; exposições, planos, modelos, $\mathrm{c}$ desenhos por elles apresentados.

Parágrafo $2^{y}$ - Memorias, e planos relativos á agricultura, commercio, navegação, industrias, sciencias, e artes com referencias a esta Provincia.

Parágrafo $3^{\text {n }}$ - Tudo o mais que possa interessar á historia d'ella" [nota: respeitada a grafia original].

Este diploma legal regeu suas atividades durante todo o período imperial, modificado, após a proclamação da República, quando foi criada, pelo VicePresidente do Estado, Dr. J. A. de Cerqueira César, em 10 de março, a Repartição da Estatística e do Arquivo do Estado, cujo artigo 1" diz:

Fica creada a Repartição de Estatistica e do Archivo do Estado, a qual se incumbirá da execução de todos os trabalhos relativos aos diversos ramo's de Estatística, conforme o Regulamento que depois expedirá o Secretario do Interior, cabendo-lhe ainda a guarda, coordenação e classificação de todos os papeis, documentos e livros attinentes ao Direito Constitucional, á Historia Política e Administrativa, á Legislação e á Geographia de São Pawlo, e de todos os demais que as autoridades competentes 
determinarem qua ali se depositem [nota: respeitada a grafia original].

De 1892 a 1957, o Arquivo do Estado foi objeto de diversas reorganizaçōes, sendo transferido de uma Secretaria de Estado para outra até que, finalmente, em 1967, fica subordinado à Secretaria da Cultura onde permanece até hojc. O Decreto $n^{2} 29922$, dc 18.10.1957, procurou disciplinar de maneira mais abrangente, minuciosa e mesmo detalhística, as funçōes, objetivos e atividades do então Departamento do Arquivo do Estado. Na ocasiāo, o Departamento de Arquivo estava subordinado à Secretaria da Educação e, no que concerne à sua estrutura administrativa, ele nāo ć inovador, pois mantém a mesma estrutura fixada no longínquo ano de 1892, com uma única modificaçāo: a Secçâo Legislativa passa a ser uma Secçāo de Expediente.

A obra de consolidaçāo do Arquivo do Estado como o principal instrumento de preservaçăo da memória do povo paulista se completa com o Decreto n" 22789 , de 19 de outubro de 1984, promulgado pelo senhor governador André Franco Montoro e que instituiu o Sistema de Arquivos do Estado de São Paulo - SAESP. Embora a criaçāo do SAESP tenha sido um passo importante no sentido de dotar o Arquivo do Estado da autoridade c competência legal para disciplinar as atividades arquivísticas no Estado de São Paulo, seu resultado foi frustrante por dois motivos principais:

7. Desde 1976, o Arquivo do Estado deixou de ser um Departamento para transformar-se numa simples Divisāo do Departamento de Museus e Arquivo da Secretaria da Cultura. É bem sabido que em países de sólida tradiçāo cultural e histórica, os arquivo do Estado, para poderem exercer sua autoridade e competência, se situam nos altos escalōes da hierarquia administrativa. Como uma simples Divisão jamais terá a possibilidade de exercer com eficiência e racionalidade suas finalidades.
2. Desde 1893, o Arquivo do Estado se vê a braços com o problema de nāo possuir instalaçōes ade. quadas às suas funçöes. Há 103 anos, este Arquivo, vem buscando, através de sucessivas mudanças, uma "casa própria" capaz de abrigá-lo com todas as comodidades que devem existir num arquivo moderno: depósitos adequados para a preservação da documentação, sala de consulentes, laboratórios de pesquisas químico-biológicas, de microfilmagem, fotográfico, sala de exposiçōes ctc. Hojc, cstamos próximos dessa realidade desde que concluídos os trabalhos do prédio localizado à Rua Voluntários da Pâtria, 596, que abrigará, finalmente, com segurança e comodidade todos os seus accrvos. Isto também permitirá que o Arquivo Intermediário - coraçāo e pulmão - do Arquivo Permanentc possa exercer suas funçōes junto aos demais órgãos da Administraçāo Pública direta e indircta, conforme cstabelecido no SAESP. Com isso, não apenas enriqueceríanos os acervos do Arquivo com a documentação produzida neste século, mas aliviaríamos essas Secretarias do peso morto de uma documentação muitas vezes inútil para si e para a História. Não se pode deixar também de assinalar que, com essa providência, os cofres públicos seriam aliviados de despesas absolutamente inúteis em aluguêis, ou poderiam ser recuperados espaços; nos edifícios $\mathrm{cm}$ que se abrigam as Secretarias, para serem utilizados de maneira mais racional.

Esse rápido e incompleto esboço histórico abre caminho para que sc possa falar do que é rcalmente importante no Arquivo: seus acervos. São eles que constituem sua razāo de ser e são eles que, hoje, estāo mais ameaçados pela precariedade das suas instalações, pela insuficiência de pessoal qualificado, pela ausência de investimentos em sua infra-estrutura. Desses acervos podemos destacar os seguintes:

A. Acervo pré-republicano, constituído de uma preciosa documentaçāo, cuja origem remonta ao 
século XVI e vai até o século XIX. Esses documentos estão acondicionados em cérca de 10000 caixas de metal, cujo conteúdo deveria passar por um processo de desinfecção, identificação, classificaçāo, catalogação e microfilmagem. É, sem dúvida, o mais precioso acervo do Arquivo e sua destruiçāo - como o que ocorreu com o acervo do Arquivo do Paraná - scria uma tragédia irremediável. $O$ atual cdifício do Arquivo é um convite a um desastre dessa natureza.

B. Acervo Deops - documentaçāo recentemente recebida pelo Arquivo do antigo Departamento de Ordem Política e Social, constituído de dossiês e prontuários da polícia política, abrange o período de 1924 atć 1983. Este é o acervo atualmente mais consultado por pesquisadores, advogados, membros dos diversos comitês de direitos humanos, poder judiciário, familiares de desaparecidos e pelos próprios fichados, alćm, claro, da imprensa escrita, falada e televisiva.

C. Acervo do jornal Última Hora, adquirido junto à família de seu fundador o jornalista Samuel Weiner, constitui-sè basicamente de jornais, fotografias, negativos, charges etc., que retratam um período significativo da nossa história e da história da imprensa no Brasil.

D. Memorial dos Governadores - acervo constituído de papéis, fotografias, documentos oficiais, particulares $\mathrm{c}$ outros dos governadores paulistas. O primeiro acervo a ser identificado, classificado e ordenado é o de Washington Luís. Este é um dos grandes projetos do Arquivo que pretende obter a documentação dos diversos governadores paulistas até os dias de hoje.

E. Acervo Fapesp - constituído das teses feitas nas universidades brasileiras e estrangeiras com financiamentos da Fundação de Amparo à Pesquisa do Estado de São Paulo, documentação imprescindível para a história das ciências no Estado de São Paulo.

Com a desativação do Baneser no início deste ano, a situação do Arquivo, no que se refere ao seu quadro funcional, tornou-se dramática, pois, de um dia para o outro, perdemos mais de $50 \%$ dos funcionários e técnicos. Em virtude das limitaçōes impostas, fomos obrigados a desativar todas as atividades do Arquivo que não tinham relação direta com o atendimento de seus consulentes. Assim, foram desativados os setores de publicação, conservação e restauração. Por outro lado, os salários foram drasticamente diminuídos de modo que, hoje, os funcionários que possuem nível universitário recebem um salário de R\$ 500,00.

Diante desse quadro constrangedor, quando os funcionários do Arquivo do Estado iniciaram seu movimento SOS-CIDADANIA - O Arquivo do Estado de São Paulo está morrendo, não estavam eles apenas pensando em scus salários, o que seria perfeitamente normal, mas, antes de tudo, desejavam preservar um patrimônio histórico que nāo é apenas do Estado, mas de toda a sociedade paulista. Que é um patrimônio da sociedade, ficou comprovado pelas inúmeras manifestações de apoio recebidas pelo movimento, dos mais diferentes segmentos da intelectualidade e da população paulista e brasilcira. Por isso, não posso deixar, ao terminar este breve relato sobre o Arquivo do Estado, de reafirmar que os problemas atuais por elc vivido demandam uma solução urgente e conjunta. Esta não deve emanar apenas do Executivo paulista, mas também podem contribuir efetivamente as agências financiadoras estatais, estadual ou federal, a Fapesp, o CNPq, o Ministério da Cultura e a própria Presidência da República, ocupada hoje por um professor universitário que iniciou sua carreira de pesquisador neste Arquivo do Estado de Sāo Paulo. 